\title{
La fábrica de azúcar de Torre del Mar, elemento de un paisaje histórico
}

\section{LAS VEGAS DE LA AXAROUÍA, UN ORIGINAL PAISAJE AGRO-INDUSTRIAL}

El origen del cultivo de la caña y fabricación del azúcar data en La Axarquía desde la época nazarí, contando con su presencia en nuestro entorno hasta el siglo XXI. La instalación fabril más antigua de la que tenemos noticias concretas, ya en época cristiana, es la del Ingenio Alto de Torrox, que era propiedad de moriscos y cristianos viejos antes de la rebelión morisca de 1569 .

Durante mucho tiempo llegó a establecerse un paisaje industrial y agrario en torno al sector azucarero, basado en el cultivo de la caña en las vegas costeras mediterráneas, y en la fabricación de azúcar y sus derivados en los trapiches, ingenios y fábricas de la zona.

En La Axarquia aún hay testimonios que nos dan idea de aquel paisaje azucarero. La caña ha dejado de cultivarse definitivamente después del cierre reciente de la fábrica de Salobreña (costa de Granada), quedando aún algunas manchas residuales de este cultivo en algunas vegas. En el aspecto industrial todavía podemos contemplar bastantes elementos de interés: el ingenio de Frigiliana, fundado en el siglo $X V I I$, es el único que aún sigue en funcionamiento como fábrica de miel de caña. Respecto a otros edificios y artefactos, se conservan de diversas épocas. Destacan las ruinas de dos ingenios preindustriales del siglo XVI, milagrosamente en pie todavía: el de San Antonio Abad en Nerja y el de Armengol en Maro. De la época industrial quedan las ruinas de los edificios de las azucareras San Joaquín de Maro, San Rafael en Torrox, Nuestra Señora del Carmen en Torre del Mar y San José en Nerja, entre otros. Relacionado con el de San Joaquin está el impresionante y bello acueducto del Águila catalogado como BIC por la Junta de Andalucia.

\section{EL INGENIO DE TORRE DEL MAR, PRIMERA FÁBRICA INDUSTRIAL DE LA COMARCA}

La industria azucarera en Torre del Mar se inició en 1796, año en el que José García Navarrete solicitó autorización para la construcción de un ingenio. En 1799 ya se encontraba terminado el edificio y en 1810 el viajero William Jacob nos habla de él: el molino para moler cañas consiste en tres cilindros de hierro perpendiculares, movidos por mulas, que exprimen el jugo que se conduce desde aqui por trojes de madera a las calderas.

Ramón de la Sagra, filósofo y empresario -emprendedor, diríamos hoy-, impulsó en 1845 la creación de la "Sociedad Azucarera Peninsular" con objeto de introducir la industrialización en el sector, y en 1846 levantó una fábrica azucarera moderna en el anterior ingenio de Torre del Mar. El proyecto fracasó al no poder instalar en ella el nuevo procedimiento de Derosne: utilización del vapor para la cocción de los jugos y empleo de centrifugadoras para la separación de la sacarosa cristalizada y la melaza. Poco después, en 1852, la fábrica pasó a manos de Larios Hermanos y Cía., convirtiéndose en un avanzado establecimiento fabril denominado Nuestra Señora del Carmen.

Los Larios estarían dirigiendo 134 años la fábrica de Torre del Mar, a la vez que detentaban un gran poderío económico y político en la comarca. Durante décadas los agricultores recibian los préstamos necesarios para emprender las cosechas, pero después dependian de que la Compañia Larios les comprase la producción. Hacia 1879 se habian convertido en los más importantes azucareros de España con 7 fábricas en la costa mediterránea andaluza (entre ellas Torrox, Nerja y Torre del Mar), con una capacidad de molienda de unos 6 millones de arrobas al año (el $40 \%$ del potencial de Andalucia en el sector).

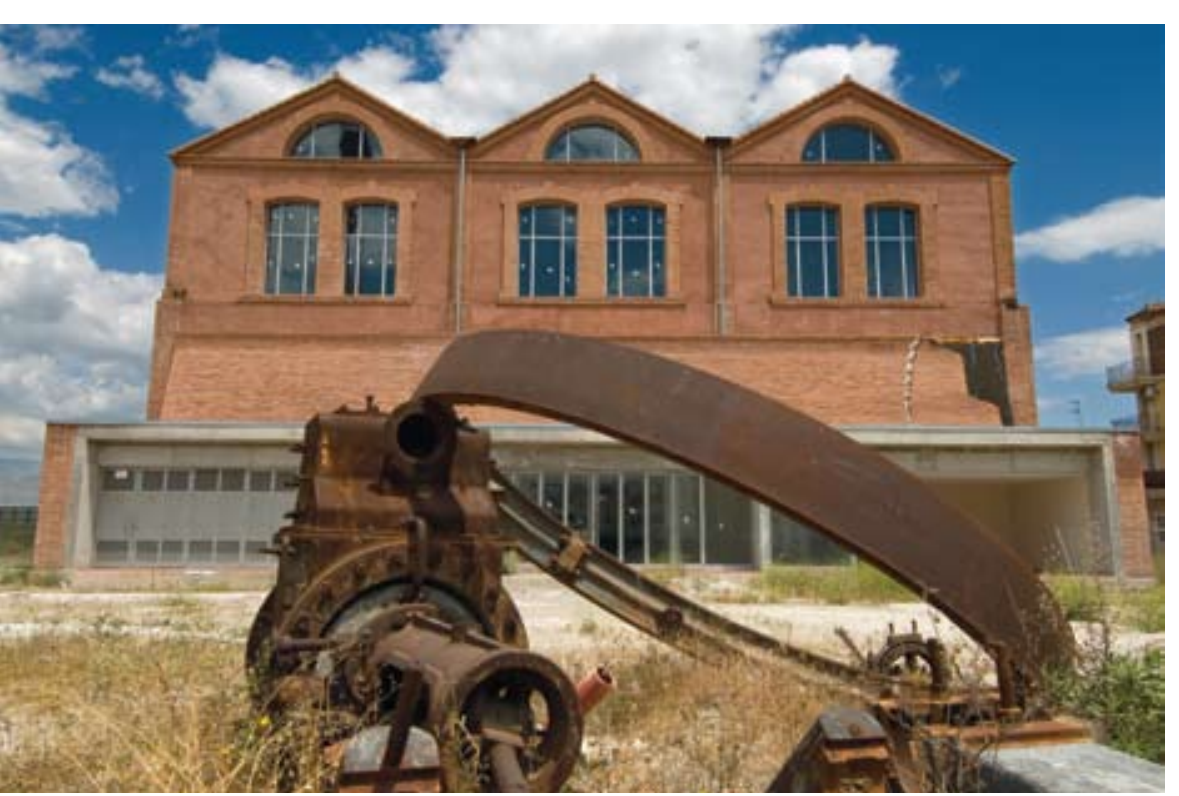

Fachada de la azucarera de Torre del Mar. Foto: Juan Carlos Cazalla, IAPH

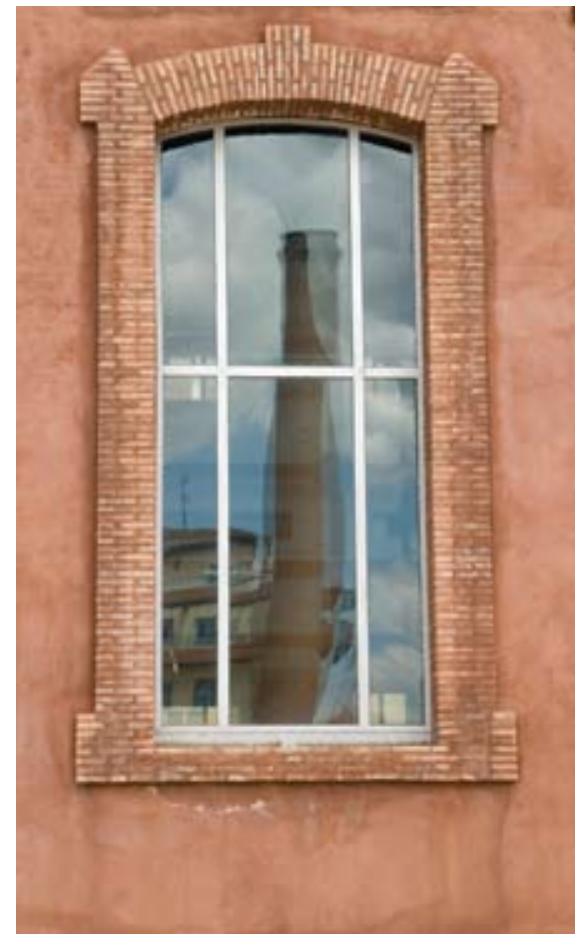

Ventanal de la azucarera de Torre del Mar. Foto: Juan Carlos Cazalla, IAPH

En 1903, se originó una crisis de sobreproducción motivada por la puesta en marcha de más de 20 nuevas fábricas de remolacha azucarera. Ante esta situación se constituyó la Sociedad General Azucarera de España, al objeto de reorganizar el sector. Durante el primer tercio del siglo XX se cerraron 36 instalaciones a instancias de la Sociedad General Azucarera, algunas de ellas con pocos años de antigüedad. Mientras tanto los Larios, que no participaron en la anterior Sociedad, continuaban en la comarca con su sistema de préstamos por adelantado a cuenta de las cosechas y se adueñaban de las fincas de pequeños propietarios y arrendatarios.

Al llegar la década de 1940 todavía quedaban funcionando en La Axarquía, sin contar algunos ingenios y trapiches menores, las fábricas de San Rafael en Torrox, San José en Nerja y Na. Sra. del Carmen en Torre del Mar. Después, en los años 70, se produce la liquidación de la caña como recurso productivo en la costa andaluza. En 1976 en Torre del Mar, única fábrica ya en funcionamiento de La Axarquia, ante la crisis empresarial, la Cooperativa Sindical Comarcal de Productores de Azúcar y Remolacha acordó la compra de la misma a la Sociedad Azucarera Larios.

En 1982, ante la prohibición de la importación de melazas, la compañia Ron Bacardí formó una sociedad con la Cooperativa Cañera para obtener ron de calidad: así surgió la Sociedad Azucarera del Mediterráneo S. A. (SAMESA). En 1986 Bacardí vendió sus acciones a la Azucarera del Guadalfeo, que pasó a controlar la fábrica como socio mayoritario. Desde 1988 la producción de caña empezó a disminuir de 


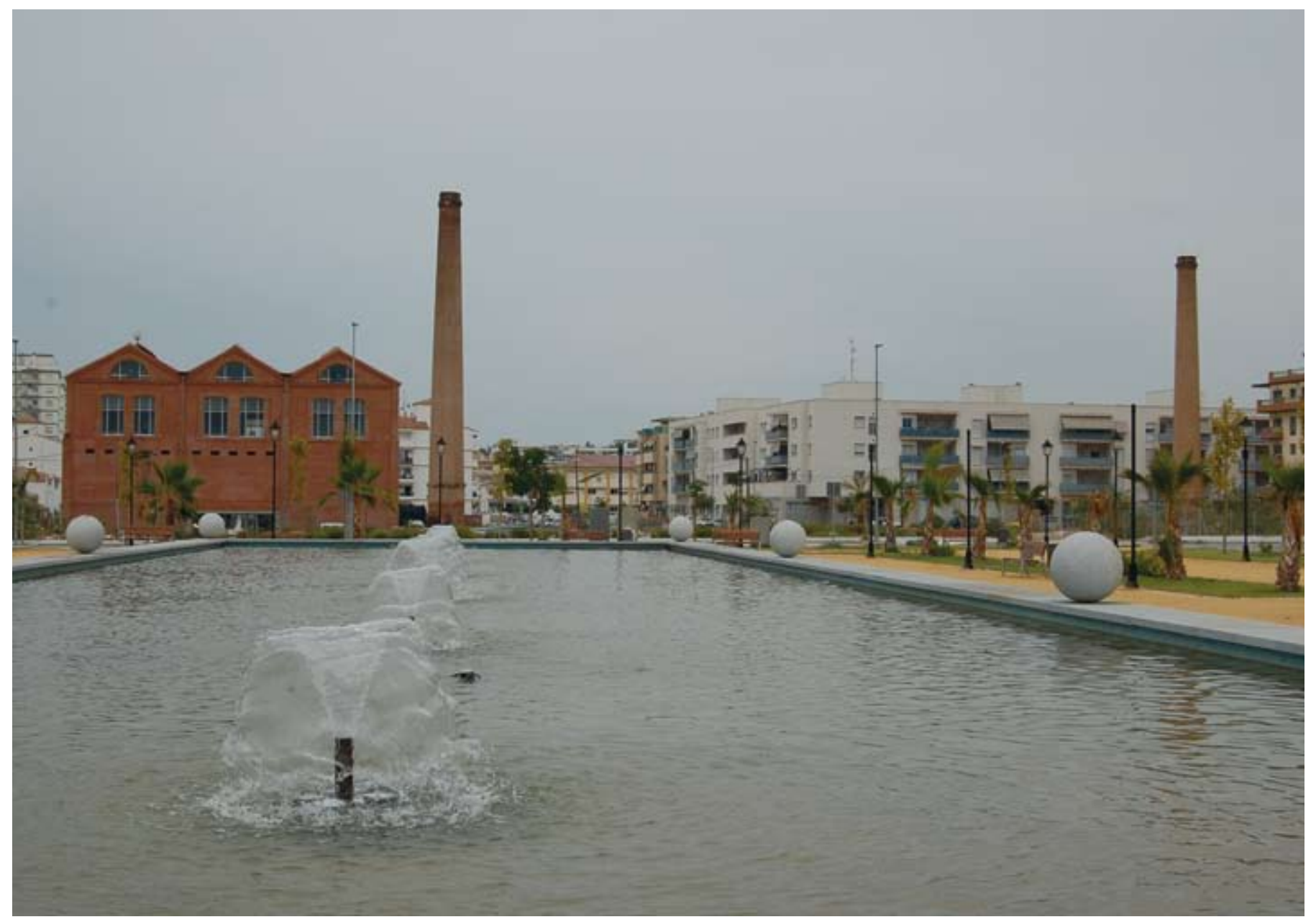

La azucarera de Torre del Mar está integrada en el casco urbano del municipio. Foto: Juan Carlos Cazalla, IAPH

forma drástica y en 1991 se dio la última campaña en Torre del Mar.

\section{EL EDIFICIO COMO ELEMENTO CULTURAL DE UN NUEVO PAISAJE URBANO}

En 1993, después que los chatarreros habian sacado las piezas más valiosas, se firmó un convenio entre el Ayuntamiento de Vélez-Málaga y la Sociedad Azucarera del Mediterráneo S. A. (SAMESA) por el que se acordaba la rehabilitación del edificio central de la fábrica, contemplando la demolición de los cuerpos añadidos, a fin de su conversión en Museo del Azúcar. El convenio quedó en letra muerta durante mucho tiempo respecto a los planes con el edificio de la fábrica. Sin embargo la denominada Casa del Ingeniero, edificada en 1888, fue rehabilitada para acoger la tenencia de alcaldia de Torre del Mar. En 1999 se restauró por la Consejería de Turismo una máquina de vapor fabricada en 1900 por la compañia Fives-Lille, y se emplazó como monumento delante de la citada Casa del Ingeniero.

En 2003 a través de la Consejería de Turismo se acometió de nuevo un plan de rehabilitación del edificio central de la fábrica al objeto de convertirlo en Centro de Difusión Turística. El proyecto, firmado por Francisco González, contempla los siguientes usos: en la planta inferior, museo del azúcar y salón de actos; en la planta primera, biblioteca, aulas y despachos; en la segunda y tercera, oficina de turismo y espacio expositivo. A la vez se prevé la integración de las tres

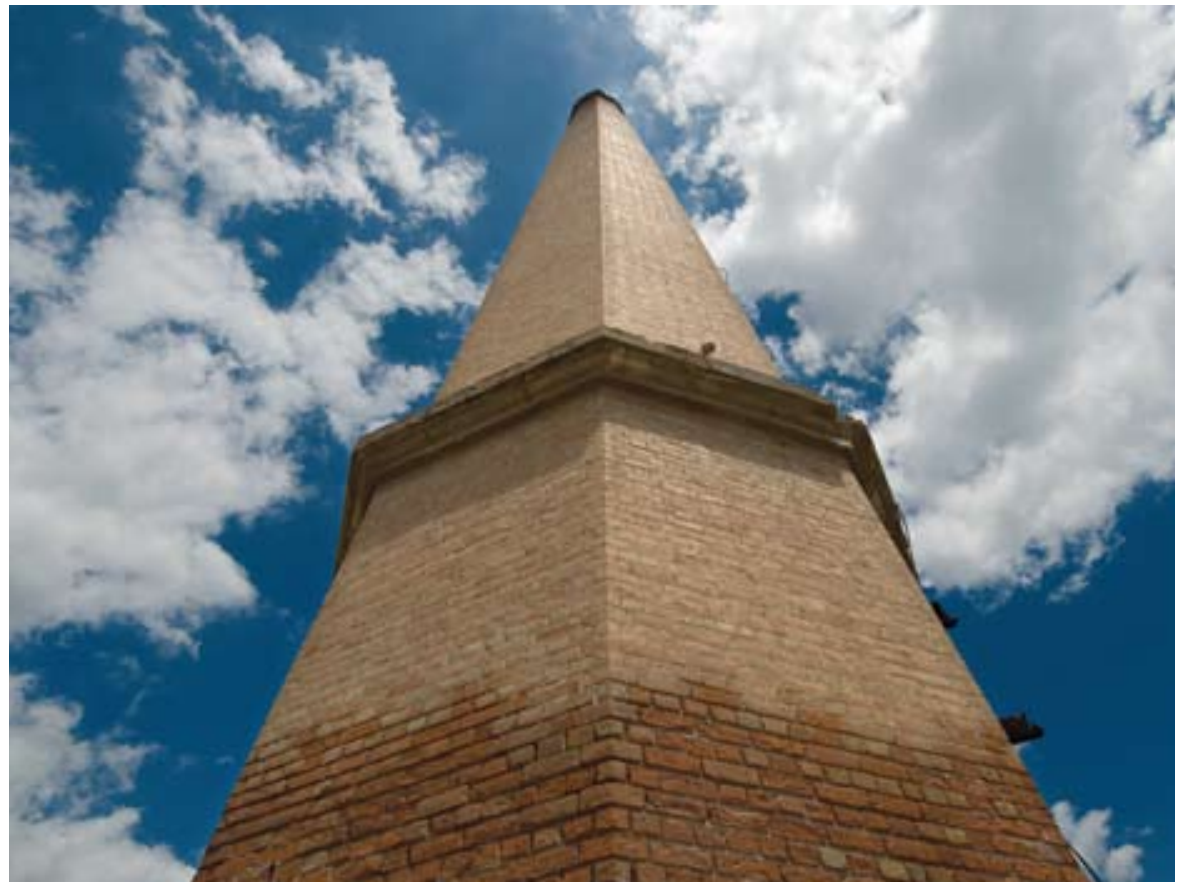

Perspectiva vertical de la antigua chimenea de la azucarera. Foto: Juan Carlos Cazalla, IAPH

chimeneas en el área urbana de la zona. El edificio industrial conservado pertenece a una ampliación realizada por Larios en torno a 1900.

Después de muchos años de abandono, la maquinaria que quedaba en estos momentos era escasísima, y se propuso la conservación de algunos compresores de carbono, malaxadores, tachas y piezas complementa- rias, que permanecian abandonadas entre las ruinas, para integrarlas como elementos decorativos. En la actualidad se siguen realizando las obras de rehabilitación del edificio.

Antonio Guzmán y Antonio Santiago

Investigadores del patrimonio industrial de Málaga 